August 2019

\title{
Spatial analysis of demand for sparsely-located ecosystem services using alternative index approaches
}

\author{
Rubén Granado-Díaz \\ José A. Gómez-Limón \\ Macario Rodríguez-Entrena \\ Anastasio J. Villanueva
}

Paper to be published in

European Review of Agricultural Economics

Editorial: Oxford Academic ISSN: 0165-1587

https://doi.org/10.1093/erae/jbz036 


\title{
Spatial analysis of demand for sparsely-located
}

\section{ecosystem services using alternative index approaches}

\author{
Granado-Díaz, Rubén; Gómez-Limón, José A.; Rodríguez-Entrena, Macario; Villanueva, Anastasio J. \\ WEARE-Water, Environmental and Agricultural Resources Economics Research Group, Universidad de \\ Córdoba
}

\begin{abstract}
This study is focused on the effects of spatial discounting and substitute sites on the demand for ecosystem services (ES) provided by scattered agroecosystems. New ways of modelling these two effects are proposed, relying on area-based and density-based indexes. Data from discrete choice experiments are used, based on a case study of Andalusian olive groves (southern Spain). The results show that model fit is significantly improved by the introduction of these spatial indexes, with the best outcome found for the area-based index combined with the inverse of the distance. Results provide evidence of substantial spatial heterogeneity depending on the ES (carbon sequestration, soil conservation and biodiversity), indicating different economic jurisdictions.
\end{abstract}

Keywords: spatial discounting, economic jurisdiction, ecosystem services, choice experiments, olive growing

JEL classification: Q11, Q51, Q57

\section{Introduction}

Agricultural systems provide a wide range of ecosystem services (ES). These include regulation of the water cycle, soil conservation, carbon sequestration, support for biodiversity and cultural services (aesthetics, recreational, etc.), among others (Swinton et al., 2007). Most services are demanded by society (Salazar-Ordóñez and Sayadi, 2011), but they lack markets to adequately incentivize their provision. As a result, governments usually play a significant role in promoting the provision of ES by agricultural systems at the socially-desired levels (Pannell, 2008; Rocamora-Montiel, Colombo and Salazar-Ordóñez, 2014). However, these levels are often unknown given the lack of information about the value attached to the ES. Therefore, the economic valuation of these non-market services is utterly essential to support policy decision-making aimed at promoting a smart provision of ES by agricultural systems (Rogers et al., 2015).

The economic valuation of ES has been the subject of much research, with special emphasis on natural sites (see Ferraro et al., 2012 for an extensive review) and, to a lesser extent, agroecosystems 
(Madureira et al., 2013). Within the specialised literature, the need to incorporate the spatial dimension has long been evidenced (e.g. Loomis, 2000; Perrings and Hannon, 2001; Schaafsma, 2015). Spatially-explicit information on values derived from ES is important for two main reasons: to determine economic jurisdiction and to inform decision-making on benefit-transfer. With regard to the former, it is the key to determine the size of the economic jurisdiction for each case, so that it reflects the geographical area where the people with significant willingness to pay (WTP) for environmental improvements (the beneficiaries) live. Thus, total welfare changes are estimated as the aggregate WTP of individuals living in that jurisdiction (Bateman et al., 2006). Moreover, information on the economic jurisdiction is useful to determine the most suitable political jurisdiction to manage the design, implementation and financing of environmental policy instruments (Loomis, 2000). With regard to benefit-transfer applications, their accuracy can be improved by using information on the spatial heterogeneity of WTP for environmental services, thus reducing transfer errors (Colombo and Hanley, 2008; Johnston, Besedin and Holland, 2019).

Studies focusing on spatial analysis of individuals' preferences toward ES have shown a variety of effects relating to spatial factors. Among these, distance-decay (i.e. the negative relationship between values and the distance between the site of supply and the individual's residence) probably stands out as the most widely known (Hanley, Schläpfer and Spurgeon, 2003; Bateman et al., 2006). However, there are other spatial factors that influence the values attached to ES, which revolve around the type of value (use and non-use) attached to the service (Hanley, Schläpfer and Spurgeon, 2003), the presence of substitutes in the nearby areas (Jørgensen et al., 2013) and directional aspects (Agee and Crocker, 2010; Schaafsma, Brouwer and Rose, 2012). While distance-decay seems to be present in a vast majority of cases (Johnston, Besedin and Holland, 2019), recent contributions call into question the prevalence of this effect over other spatial factors, especially substitutability (Lizin et al., 2016; Czajkowski et al., 2017; De Valck et al., 2017), showing that there are still unresolved issues in this field. These issues particularly refer to the circumstances under which distance-decay is noticeable and the valuation of sparsely-located ES. With regard to the occurrence of distance-decay, there are still unknowns regarding the extent to which the distance-decay effect persists for ES with significant nonuse values, and how the intensity of this effect varies according to directional aspects and the presence of substitutes with differing characteristics and spatial distribution (Schaafsma, 2015) (see next section for further explanation). These factors clearly point to the inadequacy of focusing spatial analysis only on the concept of 'distance-decay', as the traditional distance-based assessments notably fail to incorporate substitutability and directional issues into the analysis. In light of this, it is worth considering broader approaches accounting for other spatial measures such as area (size of the site near the individual's residence in absolute terms, without considering the existence of possible 
substitutes) or density (size of the site relative to the size of alternative sites in the area surrounding the individual's residence, with the aim of accounting for the existence of possible substitutes), both focusing on the more general concept of 'spatial-heterogeneity' or 'spatial-discounting'.

Additionally, spatial assessments of WTP for ES have regularly focused on the analysis of single concentrated sites (e.g. a natural park), while more complex locations, such as sparsely-located sites, have received much less attention. Although a few applications have focused on sites of the latter type, including forest areas (Czajkowski et al., 2017) and riparian zones (Holland and Johnston, 2017), to the authors' knowledge there is no study directly focusing on agricultural systems. If we consider substitutability and directional issues, it can be readily inferred that distance-decay models may perform poorly compared to area- and density-based models when applied to these sparsely-located ecosystems (Lizin et al., 2016; Budziński et al., 2018).

Therefore, this paper aims to contribute to the existing literature in two ways: first, by providing empirical evidence on the spatial heterogeneity of values derived from the ES provided by sparselylocated agricultural systems; and second, by delivering methodological insights into the use of different area- and density-based approaches to analyse such heterogeneity. To achieve both objectives, we use data from a discrete choice experiment carried out to valuate individuals' WTP for ES, based on a case study of the olive grove agricultural system in Andalusia (southern Spain). We use a continuous mixture logit approach to explore heterogeneity with different area and density indexes, which, to our knowledge, are used here for the first time on agricultural systems.

\section{Spatial heterogeneity and environmental valuation}

\subsection{Main spatial factors affecting WTP for ES}

The existing literature identifies several spatial factors influencing households' welfare estimates for environmental improvements (i.e. WTP), particularly revolving around the distance from and the type of value (use vs. non-use values) of the ES, as well as the existence of close substitute sites providing the same ES.

According to economic theory, the "net utility" obtained from non-market goods and services depends on their characteristics (quantity and quality) and the disutility of the costs borne by individuals in order to consume or use them. As such, individuals' preferences are driven by distancedependent utility functions since the accessibility to non-market goods and services depends on the distance from the individual's home to the provision place (e.g. involving travel costs). Based on this, the spatial discounting theory captures individuals' preferences for consumption at a given location relative to consumption at some distance from that location (Perrings and Hannon, 2001). There is 
empirical evidence that this theory applies for ES, explaining the distance-decay preferences for environmental changes; that is, the closer people live to the environmental resources, the stronger their concerns about changes affecting those resources (i.e. higher WTP for improvements or WTA for deterioration) ${ }^{1}$. Schaafsma (2015) points out that among a large number of studies accounting for the effect of distance on WTP for ES, about 85\% find a distance-decay effect.

The rationale described above provides a clear theoretical foundation for distance-decay in ES with use values (e.g. those related to recreation), but there is no theoretical expectation for the spatial discounting of non-use values (i.e. bequest, altruistic and existence values). In this sense, the empirical evidence is not conclusive, very likely due to the difficulty in distinguishing between use and non-use values, which largely stems from the fact that the kind of value awarded by individuals to ES differs depending on whether they are users (who hold use and non-use values) or non-users (who hold option and non-use values) (Bateman et al., 2006). Almost all studies reporting a relationship of independence between distance and WTP justify their results on the basis that they focused on ES with mostly nonuse values and/or non-users' preferences (e.g. Pate and Loomis, 1997; Bateman et al., 2006). However, there are also studies that find distance-decay effects in WTP for ES with non-use values and/or among non-users (e.g. Hanley, Schläpfer and Spurgeon, 2003; Jørgensen et al., 2013). Distance-decay in these cases can be explained by a cultural identity dimension linked to non-use values, also referred to as "sense of place", "spatial identity" or "sense of ownership" (Hanley, Schläpfer and Spurgeon, 2003), meaning that non-users who live closer express relatively higher non-use values. In this regard, Bateman et al. (2006) and Jørgensen et al. (2013) argue that a negative correlation between WTP and distance for non-users may express their option values (possible future conversion into users under certain circumstances - e.g. improved provision of ES).

In any case, it is widely recognised that a higher spatial discount rate exists for ES with use values (or users) than for ES with non-use values (or non-users) (Hanley, Schläpfer and Spurgeon, 2003; Schaafsma, Brouwer and Rose, 2012; Jørgensen et al., 2013; Schaafsma et al., 2013).

The availability of substitutes (goods satisfying the same needs) is another factor causing distancedecay in sites providing ES. The existence of substitutes influences the relative scarcity of ES, thus affecting the WTP for them. According to economic theory, as marginal utility declines with every available unit, the larger the number (or size) of substitutes, the lower the WTP for these substitutes

${ }^{1}$ In addition to the distance (i.e. travel costs), distance-decay can be also explained by other individual-specific features, such as visitation rates, cultural identity, or information and knowledge about the good under valuation, all of which are common explanatory variables in many valuation studies. Nevertheless, distance shows a strong negative correlation with all these variables (Pate and Loomis, 1997; Brody, Highfield and Alston, 2004; Concu, 2007). 
(or size units). Taking into account the fact that the availability of substitutes for a particular natural site often increases with distance from the individuals' home (increase in supply), individuals are expected to have lower WTP for improvements to that site (decrease in demand) as the distance from their home increases. A large body of empirical evidence confirms this theory (e.g. Pate and Loomis, 1997; Brouwer and Slangen, 1998). In fact, Jørgensen et al. (2013) suggest that the distances to substitutes are stronger drivers of spatial preferences than the distance to the natural site subject to valuation.

However, most of the studies focusing on spatial heterogeneity in WTP have estimated isotropic (one-dimensional) distance-decay effects, implicitly assuming distance-decay to be uniform in all directions because of the absence of substitutes or their random spatial distribution. This oversimplified approach ignores the effects on spatial heterogeneity caused by the presence of actual substitutes; as a result, valuation exercises fail to produce accurate and reliable WTP estimates (Schaafsma, Brouwer and Rose, 2012; Schaafsma et al., 2013). Different approaches have been proposed to gain a better understanding of variations in distance-decay due to substitutes that are not randomly distributed over space. The most obvious is to include the distance to substitutes as additional variables in the analysis. However, this option entails the difficulty of identifying a selection of relevant substitutes (Haab and Hicks, 1997). Other possibilities for dealing with this problem rely on the use of anisotropic (two-dimensional) analyses, accounting for spatial heterogeneity by considering different distance-decay effects depending on the direction. The first option for this two-dimensional analysis is the spatial expansion method, which includes spatial trend variables using polar coordinates (longitude $x$, latitude y) of the observation (Cameron, 2006; Schaafsma et al., 2013). A second option is to divide the sample of respondents into subsamples lying in different compass directions, using dummy variables for the site corresponding to the respondent (Agee and Crocker, 2010; Schaafsma, Brouwer and Rose, 2012).

Other more recent approaches aimed at explaining spatial heterogeneity in WTP have focused on non-continuous spatial variation trends in distance-decay. As pointed out by Czajkowski et al. (2017), these approaches include non-parametric and parametric analyses, both of which attempt to explain spatial welfare variations based on distance measures and other spatial variables obtained from Geographical Information Systems (GIS). Non-parametric analyses combine results derived from stated preference studies with GIS data. Noteworthy examples include applications using spatial autocorrelation (Campbell, Scarpa and Hutchinson, 2008), kriging methods (Campbell, Hutchinson and Scarpa, 2009) and local indicators of spatial association or hotspots (Johnston and Ramachandran, 2014; Johnston et al., 2015). Parametric analyses also use spatial proximity measures and other spatial variables such as density measures accounting for the presence of substitutes, in addition to 
respondents' socio-demographic characteristics, as explanatory variables to unravel variations in individual WTP for environmental changes. The most recent empirical applications of this approach are Abildtrup et al. (2013), Yao et al. (2014), Nielsen, Lundhede and Jacobsen (2016), Czajkowski et al. (2017) and Budziński et al. (2018).

\subsection{Location features of environmental sites}

Commonly, the ES analysed in the spatial heterogeneity literature are provided by one specific natural site, which is usually spatially concentrated (i.e. located within a spatially-contiguous site), such as green areas, national parks, lakes, etc. This case is represented in Fig. 1a, where points A to D denote the location of four potential households that benefit (or suffer) from use (e.g. recreation and scenery) and non-use (e.g. wildlife conservation) ES provided by this site. Under this circumstance, the distance from these households can be easily measured by considering the nearest point of the site (i.e. geographic distance) $)^{2}$. Thus, assuming distance-decay effects, households $A$ and $B$ are expected to have more intense preferences (they are more 'exposed') toward changes in the supply of environmental services than households C and D. Moreover, when the site is spatially concentrated, the distance and the quantity of the natural site affecting individuals are usually highly correlated. As can be inferred from Fig. 1a, the site area affecting $A$ and $B$ is also much larger than that affecting $C$ and D. Thus, in the case of concentrated sites, failing to account for quantity is not a relevant issue since analysing distance-decay indirectly takes into account quantity-decay.

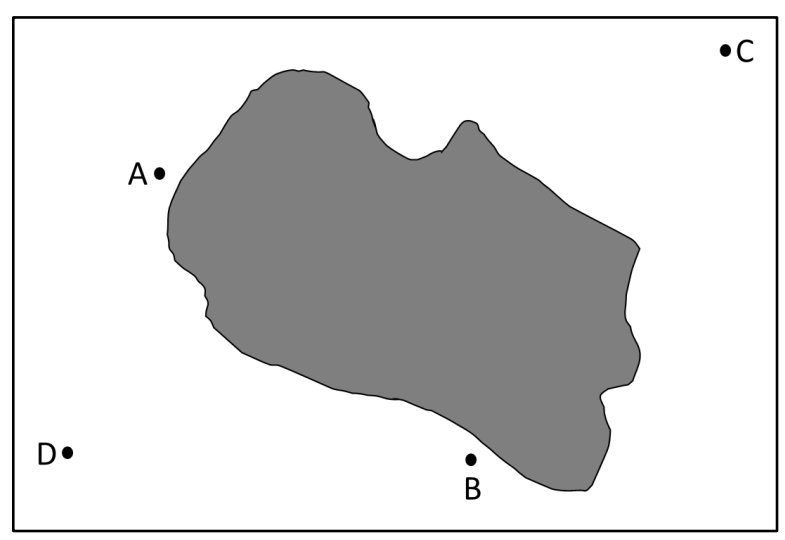

1a. Concentrated environmental site

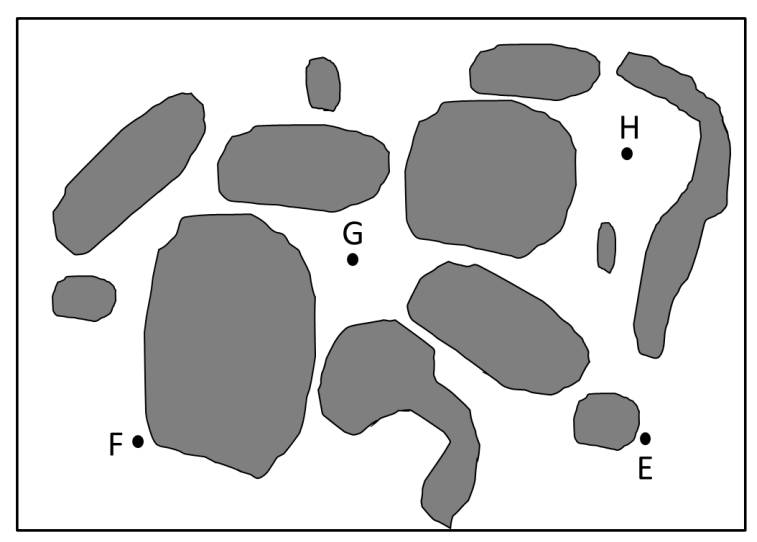

1b. Scattered environmental site

Fig. 1. Concentrated vs. scattered environmental sites.

2 Other measures of distance are available, both objective (route distance or travel time) and subjective (expected travel time or based on mental maps). Subjective distance measures such as the perceived travel time are considered to be the most suitable factor for determining the disutility of the costs individuals face in order to consume or use ES. However, as shown by Concu (2007), objective distance measures such as geographical distance ('as the crow flies') are highly correlated with perceived travel time, thus representing a good proxy of subjective measures. 
Now consider a scattered or spatially-dispersed environmental site (over multiple non-contiguous locations) such as the one shown in Fig. $1 \mathrm{~b}$, also providing use and non-use ES. One can see that households $E$ and $F$ are closer to the site (shorter distance) than households $G$ and H. However, it can also be intuitively understood that households $\mathrm{G}$ and $\mathrm{H}$ are more affected by or 'exposed' to the environmental site, as they benefit (or suffer) from the greater area in their surroundings. In these cases, the inclusion of only distance-decay effects may be misleading as to the true spatial determinants of WTP, probably leading to inaccurate estimates. In fact, in Fig. 1b, contrary to what is suggested by the distance analysis, households $\mathrm{G}$ and $\mathrm{H}$ would plausibly have more intense preferences toward environmental changes than households $\mathrm{E}$ and $\mathrm{F}$.

The above-mentioned facts suggest that accounting for the quantity (or the site area) of the ES affecting households (instead of the distance from the site) may better characterise spatial welfare heterogeneity. However, there are only a few previous studies that have considered quantity- or areabased approaches. The first such attempts estimated separate valuation models for respondents in different space regions (districts, subbasins, municipalities or grid squares on a map) where the quantity or the site area affecting households was considered to be similar for all of them (e.g. Pate and Loomis, 1997; Brouwer, Martin-Ortega and Berbel, 2010; Meyerhoff, Boeri and Hartje, 2014).

Only recently have a few stated preference analyses proposed area- rather than distance-based approaches to explain WTP heterogeneity, as more accurate methods to deal with this issue. Yao et al. (2014) calculate the amount of forestry area within predetermined distance bands of $10 \mathrm{~km}, 10-50 \mathrm{~km}$ and 50-100 km from each respondent's home, and use these area measures as independent variables explaining WTP variation. Nielsen, Lundhede and Jacobsen (2016) use a similar approach, calculating the area within a $2.5 \mathrm{~km}$ buffer of each respondent's home. Holland and Johnston (2017) propose an approach that relies on the quantity-within-distance-x, explaining WTP patterns regarding riparian land restoration in Maine (USA) based on the quantity of an affected resource surrounding each respondent within an optimised distance band or radius around each home. De Valck et al. (2017) analyse preferences for nature restoration in Flanders (Belgium) by computing the density (instead of the area) of nature sites within various ranges from each respondent's home and applying spatial discounting factors to approximate different functional forms of the density gradient effect. All these studies conclude that, compared to the classic distance-decay model, area- or density-based approaches reveal additional insights in spatial welfare analysis.

This paper adds to the existing literature by providing new evidence that area- and density-based approaches outperform distance-based models, especially when sparsely-located environmental sites are considered. Moreover, we compare area-based and density-based approaches using different formulations. In this regard, we aim to: a) test the hypothesis that the latter outperforms the former 
since density-based measures also account for the possible existence of substitutes and b) determine which formulation is more accurate when modelling the spatial heterogeneity of WTP values.

\section{Materials and methods}

\subsection{Olive growing in Andalusia}

Olive groves are the most representative agroecosystem of Andalusia. They occupy more than 1.5 million hectares (30\% of the region's Utilised Agricultural Area) and are an important element in employment and income generation in the majority of Andalusian rural areas, while also often contributing to areas of high-environmental and landscape value (Salazar-Ordóñez and Sayadi, 2011; Colombo and Camacho-Castillo, 2014; Villanueva et al., 2015a). As can be seen in Fig. 2, olive groves are mainly located in central and north-eastern areas, although they can also be found scattered across the rest of the region.

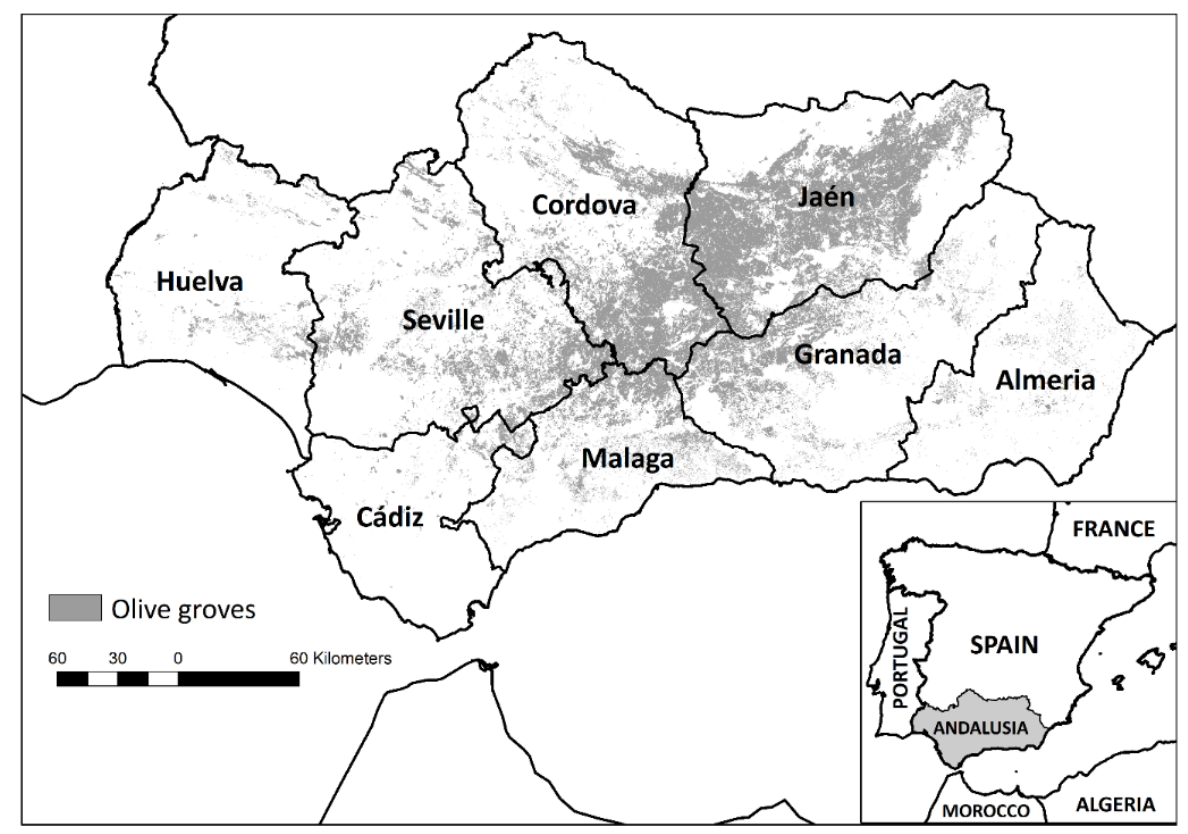

Fig. 2. Distribution of olive groves in Andalusia. Source: Own elaboration from Olive Grove Model, Foresight Department of the Agency of Agricultural and Fishing Management of Andalusia (AGAPA).

In addition to their socio-economic importance (employment and income generation), olives groves are also characterised by a remarkable provision of ES, mainly related to biodiversity, mitigation of climate change and soil conservation. With regard to biodiversity, olive groves in Andalusia have traditionally been extensively managed, typically characterised as a low-input rain-fed agricultural system associated with high levels of fauna and flora. Indeed, species closely associated with the crop-mainly semi-natural vegetation, reptiles and birds-are found extensively in traditional olive groves; as a result, this agricultural system is considered high nature value farmland (Paracchini et al., 
2008; Rocamora-Montiel, Glenk and Colombo, 2014). However, with the proliferation of new plantations, often highly-intensive monovarietal groves relying on irrigation, the monoculture of olive groves has sharply increased, resulting in growing pressures on the biodiversity associated with this agricultural system (Gómez-Limón, Picazo-Tadeo and Reig-Martínez, 2012).

When it comes to mitigating climate change, olive groves, just like any other permanent crop, can keep significant carbon stocks in their woody tissue. Additionally, they offer greater potential for carbon sequestration in soils; in particular, the use of soil-friendly management practices and organic fertilization is reported to result in remarkable improvements in carbon sequestration in olive groves (Aguilera, Guzmán and Alonso, 2014).

Olive growing also plays a significant role with regard to the provision of ES related to soil conservation. Like biodiversity and mitigation of climate change, there is great potential for improving soil conservation, especially since most of the olive groves are located in areas with moderate to steep slopes, usually suffering from high soil erosion rates. The spread of soil conservation techniques can significantly reduce the erosion risk, contributing to an improvement in soil fertility and an increase in organic matter (Gómez Calero et al., 2009).

The abovementioned ES (biodiversity, carbon sequestration and soil conservation) have different values (use and non-use values) and scales (global services versus local services). Carbon sequestration can be considered mainly as a global service (people all over the world benefit from carbon sequestration by any agricultural system), with non-use values (especially bequest value) usually more prominent than use values. Soil conservation is primarily viewed as a local service (the individuals that have the most to gain from reduced soil erosion are those who live nearby), and so use values typically prevail over non-use values. The scope of biodiversity is mixed. Whereas it can be seen as a global service (i.e. people all over the world can benefit from an increase in biodiversity in any place), its links with other services such as recreation and scenery also give it a significant local dimension. As a result, at local level, use values often prevail over non-use ones.

\subsection{Methodological proposal for spatial analysis in sparsely-located systems}

As shown in Section 2.2, the distance to environmental sites may not be a sufficiently accurate measure for explaining the heterogeneity in individuals' WTP for scattered ecosystems (as most agricultural systems are). This explains why area- and density-based approaches have been proposed for these cases as alternative approaches for spatial discounting (Yao et al., 2014; Nielsen, Lundhede and Jacobsen, 2016; De Valck et al., 2017; Holland and Johnston, 2017). However, to the authors' knowledge, none of the previous works have explicitly explained the theoretical basis justifying the use of these spatial indexes. In this regard, this paper aims to contribute to the existing literature by 
presenting the rationale behind both kinds of spatial discounting approaches. As shown below, although they depart from the traditional distance-decay approach for spatially-concentrated environmental sites, both of these spatial indexes for spatially-dispersed sites can be considered as simply a generalization of the traditional approach but in two-dimensional continuous space.

The utility associated with a spatially-concentrated site $i$ providing ES for a household $h$ can be represented by the following expression:

$$
U_{i h}=f\left(X_{k i}, Y_{h}, d_{i}, S\right)
$$

where $X_{k i}$ denotes the vector of $k$ attributes of site $i$ (i.e. ES-mix provision), $Y_{h}$ the vector of characteristics of household $h, d_{i}$ the distance between site $i$ and household $h$ and $S$ the availability of substitute sites $^{3}$.

Considering $N$ spatially-concentrated sites $(i=1, \ldots, N)$ around household $h$, the aggregate utility can be calculated as follows:

$$
U_{h}=\Phi\left(\sum_{i=1}^{i=N} f\left(X_{k i}, Y_{h}, d_{i}, S\right)\right)
$$

where $\Phi$ is a function that allows the utility to fulfil the law of diminishing marginal utility (i.e. nonlinear -concave- relationship between the number of sites and the aggregate utility). In spatial analysis, this function is usually assumed to be logarithmic (e.g. Poudyal et al., 2009; Sander and Polasky, 2009) ${ }^{4}$. Let us also assume that the $N$ spatially-concentrated sites are similar (i.e. $X_{k i}=X_{k}$; in our case study this means all olive groves are considered to provide the same ES-mix), and that there is no substitute site available near household $h$ (this strong assumption will be relaxed afterwards). These assumptions lead to the following expression:

$$
U_{h}=\ln \left(\sum_{i=1}^{i=N} f\left(X_{k}, Y_{h}, d_{i}\right)\right)=\ln \left(\sum_{i=1}^{i=N} f\left(X_{k}, Y_{h}\right) \delta_{i}\right)
$$

with $\delta_{i}$ being a distance-decay function ${ }^{5}$. This expression can be rearranged as follows:

\footnotetext{
${ }^{3}$ The variable capturing the availability of substitute sites is also a function of distance from the household and the different ES-mix provided by these substitute sites. However, for reasons of simplicity, we just refer to it as $S$, which combines all these factors.

${ }^{4}$ Note that this assumption does not imply any loss of generality. A logarithmic function has been chosen for utility instead of other suitable shapes for the sake of simplicity when expressing it mathematically.

${ }^{5}$ We are implicitly assuming that the distance-decay function is only affected by the distance to site $i$, i.e. it is the same for all households $(h)$ and all kinds of environmental sites $(k)$. However, in theory this could be individualand ES-specific. This issue will be pointed out in the conclusion section as a topic for further research aiming at developing a more general theoretical framework.
} 


$$
U_{h}=\ln \left(f\left(X_{k}, Y_{h}\right) \sum_{i=1}^{i=N} \delta_{i}\right)=\ln f\left(X_{k}, Y_{h}\right)+\ln \sum_{i=1}^{i=N} \delta_{i}=u_{k h}+\ln \sum_{i=1}^{i=N} \delta\left(x_{i}, y_{i}\right)
$$

with $u_{k h}$ being the utility provided by any site $i$ to household $h$ and $\delta\left(x_{i}, y_{i}\right)$ the distance function determined by the difference in the Cartesian coordinates of site $i$ related to household $h\left(x_{i}\right.$ and $\left.y_{i}\right)$. Fig. 3a shows an illustrative geographical representation of this case where household $h$ is located at the origin of the coordinates.

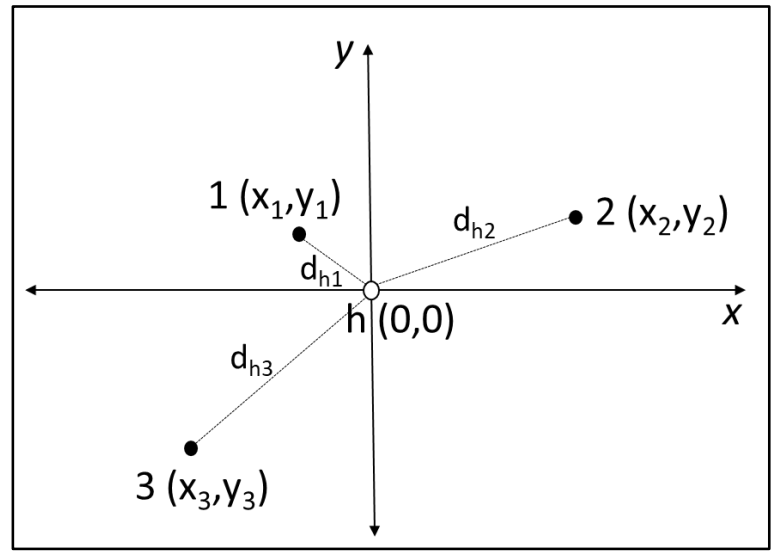

3a. Concentrated environmental site

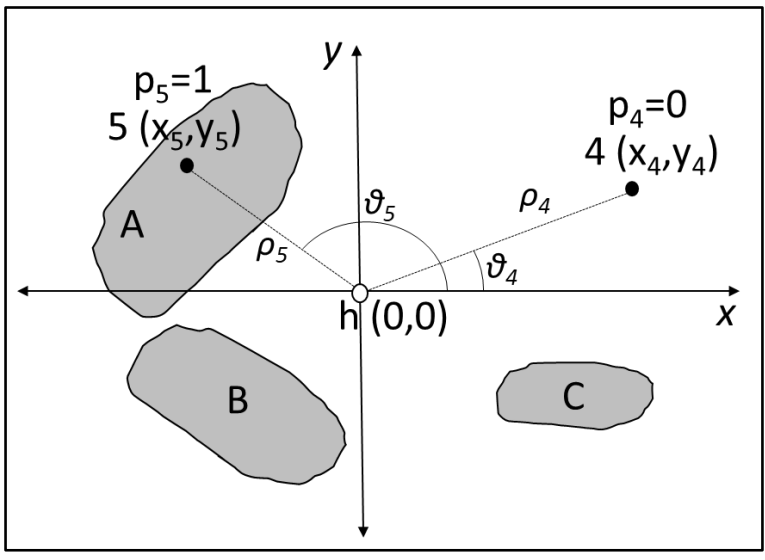

3b. Scattered environmental site

Fig. 3. Spatial discounting in concentrated and scattered environmental sites.

In case of multiple spatially-dispersed sites, as shown in Fig. 3b, the spatial analysis approach explained above can be generalised for all the continuous space as follows:

$$
U_{h}=u_{k h}+\ln \left[\int_{Y^{-}}^{Y^{+}} \int_{X^{-}}^{X^{+}}[p(x, y) \delta(x, y)] d x d y\right]
$$

where $p(x, y)$ is a dummy spatial variable taking the value 1 when the point with coordinates $(x, y)$ is included within the limits of the environmental site under analysis and 0 if located elsewhere, and $X^{+}$, $X, Y^{+}$and $Y^{-}$are set in order to define the region in terms of the two-dimensional space to be analysed (the Andalusian region in our case study). Note that the double integral between square brackets represents the total area covered by the scattered environmental site under analysis, discounted by the distance function $\delta(x, y)$. This shows that the contribution of the ES-mix provided by a spatiallydispersed environmental site to households' utility depends on the area covered by this site appropriately discounted by distance.

In order to make expression (5) more workable, Cartesian coordinates can be converted into polar coordinates (see Fig. 3b) as follows:

$$
U_{h}=u_{k h}+\ln \left[\int_{0}^{R} \int_{0}^{2 \pi} p(\vartheta, \rho) \delta(\vartheta, \rho) \rho d \vartheta d \rho\right]
$$


where $R$ is also set in order to define the spatial region to be considered. This expression allows the part of the utility depending on the spatial location of the scattered environmental site to be calculated by numerical integration.

In order to apply this spatial analysis, it is necessary to know the location of every household sampled for the empirical application. Once the location of each respondent has been identified, the next step is to calculate the area of the environmental site analysed at different distances from the household. To that end, in our case study, a set of $10 \mathrm{~km}$-wide annuli (or ring buffer zones) are created for every individual location using GIS techniques, until the whole Andalusian region is covered. These annuli are then intersected with the Andalusian olive grove cartography, thus yielding the area of olive groves included in every annulus. Fig. 4 illustrates this procedure.

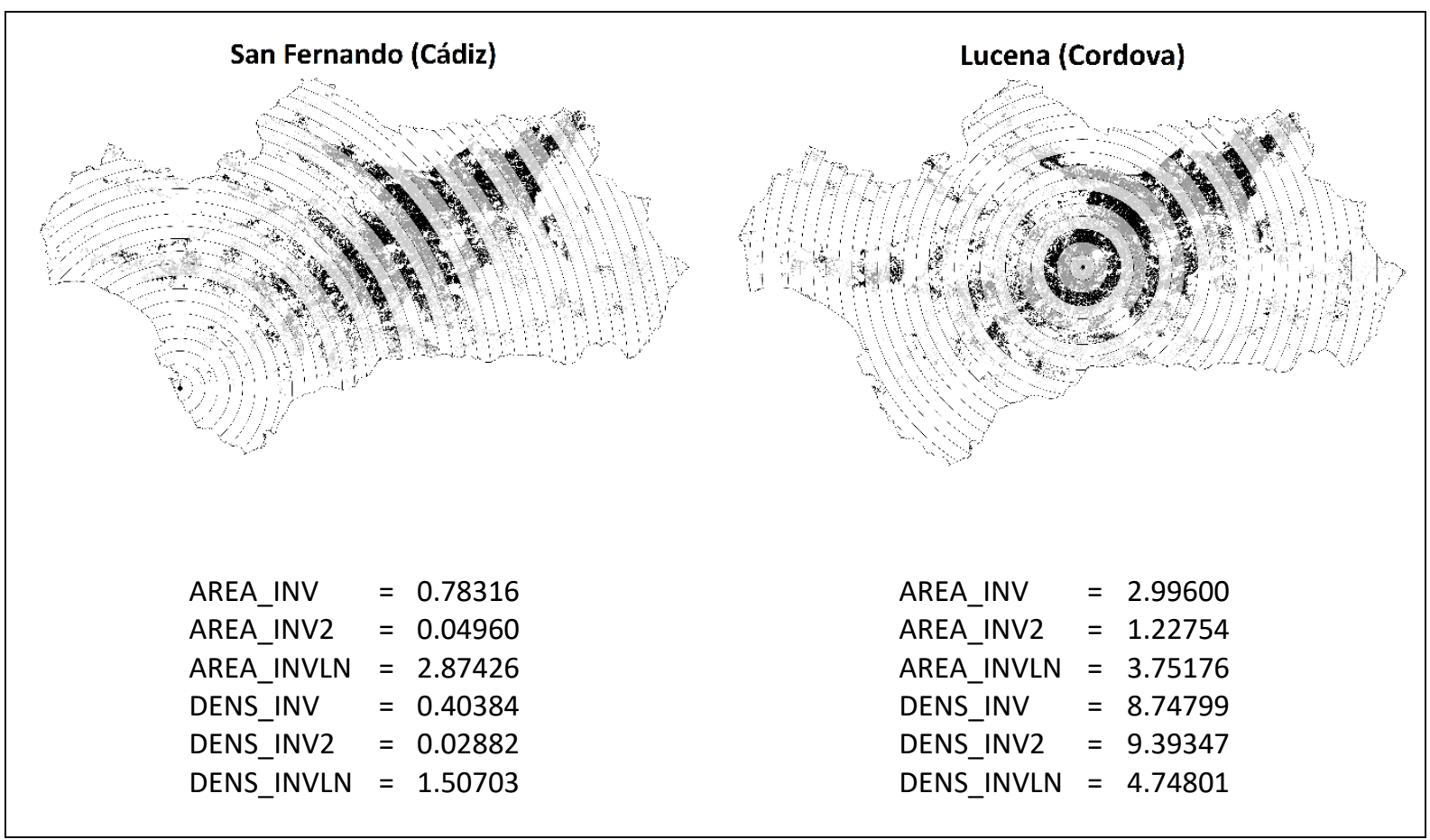

Fig. 4. Examples of the calculation of the olive growing area- and density-based indexes. Source: Own elaboration from Olive Grove Model, Foresight Department of AGAPA.

Using this information, the double integral in expression (6) is approximated by three area-based indexes calculated considering different functions for spatial discounting. For the first index (AREA_INV), the olive grove area is discounted by the inverse of the mean distance to each $10 \mathrm{~km}$-wide annulus. It is calculated using the following expression:

$$
A R E A \_I N V=\frac{1}{10,000} \times \sum_{\mathrm{a}=1}^{a=A} \frac{1}{d_{a}} \times \text { Olive_area }_{a}
$$


where Olive_area $a_{a}$ represents the area of olive groves within annulus $a$ and $d_{a}$ the mean distance between the location of the respondent and annulus $a$. The index is multiplied by a factor of $1 / 10,000$ to escalate it to approximately one unit on average.

The second area-based index (AREA_INV2) differs from the previous one in that the olive grove area is discounted proportionally to the squared mean distance:

$$
\text { AREA_INV2 }=\frac{1}{1,000} \times \sum_{\mathrm{a}=1}^{a=A} \frac{1}{{d_{a}}^{2}} \times \text { Olive_area }_{a}
$$

This index also assumes that the olive groves located nearby have a greater value than those farther away, but compared with AREA_INV, its value decreases more rapidly with distance. For the same reason mentioned above, this index is escalated by being multiplied by $1 / 1,000$.

In the third area-based index (AREA_INVLN), a logarithmic transformation of the distance is used:

$$
A R E A \_I N V L N=\frac{1}{100,000} \times \sum_{a=1}^{a=A} \frac{1}{\ln d_{a}} \times \text { Olive_area }_{a}
$$

In this case, it is assumed that the effect of the distance is smoother, and therefore the value of the olive groves located at a greater distance is higher than in the other two indexes.

In sum, all these area-based indexes are obtained by building a set of rings (annuli) around each respondent and calculating the olive grove area $\left(\right.$ Olive_area $\left._{a}\right)$ for each ring. The olive area obtained for each ring is inversely related to the distance (taken as distance, $d_{a}$; squared distance, $d_{a}{ }^{2}$; or logarithm of the distance, $\ln d_{a}$ ) from the respondent to the ring as a discounting procedure. Finally, the indexes are calculated by summing the discounted area of every ring (see Fig. 4). Thus, the larger the olive area or the closer it is, the higher the index value.

As commented above, area-based indexes ignore the existence of possible substitute sites. However, incorporating the availability of possible substitutes into the analysis is a difficult task due to the lack of information regarding the spatial heterogeneity in ES provision depending on different land uses, as well as the complexity of considering all substitutes at the same time. As an attempt to include possible substitutes into the analysis, we can assume that the environmental site analysed (olive groves in our case study) can be equally substituted by any other site. This may be a strong assumption as other sites very likely provide ES at different levels. However, it is worth considering this assumption 
in order to test whether the modelling of spatial heterogeneity can be improved by partly incorporating non-randomly distributed substitutes ${ }^{6}$.

As highlighted in Section 2, the existence of substitutes reduces the utility generated by a specific environmental site. For this reason, expression (6) can be generalised by including a new term reducing $U_{h}$ depending on the area of possible substitutes around household $h$. Considering the abovementioned assumption (all area around $h$ different than the site analysed is considered a substitute), this term can be incorporated as follows:

$$
\begin{aligned}
U_{h}=u_{k h}+\ln & {\left[\int_{0}^{R} \int_{0}^{2 \pi} p(\vartheta, \rho) \delta(\vartheta, \rho) \rho d \vartheta d \rho\right] } \\
& -\ln \left[\int_{0}^{R} \int_{0}^{2 \pi}[1-p(\vartheta, \rho)] \delta(\vartheta, \rho) \rho d \vartheta d \rho\right]= \\
& =u_{k h}+\ln \left[\frac{\text { Site_area_discounted }}{\text { Substitute_area_discounted }}\right]
\end{aligned}
$$

where the double integral in the third term denotes the area not covered by the scattered environmental site considered (possible substitute sites) discounted by the distance function $\delta(x, y)$.

Following this expression, the part of the utility depending on the spatial location of the scattered environmental site depends on its density, defined as the ratio between the site area and the area dedicated to other land uses. This part of the utility can also be calculated by numerical integration, following the same approach explained above, which entails substituting the area of the environmental site analysed within each annulus with the density of this particular site in relation to other land uses.

Mirroring the area-based indexes, three density-based indexes are proposed. Thus, analogously to expression (7), DENS_INV index is calculated as follows:

$$
D E N S \_I N V=10 \times \sum_{\mathrm{a}=1}^{a=A} \frac{1}{d_{a}} \times \frac{\text { Olive_area }_{a}}{\text { Substitute_area }}
$$

where Substitute_area $a_{a}$ represents the area of land dedicated to uses other than olive growing in annulus $a$ falling within the Andalusian region. As in the AREA_INV index, DENS_INV index is multiplied by 10 to escalate it to approximately one unit on average.

Similarly, the DENS_INV2 and DENS_INVLN indexes are calculated using the following expressions:

\footnotetext{
${ }^{6}$ The density-based approach as defined in our study incorporates non-random spatial distribution of substitutes, as their location is incorporated into the indexes by including in the denominator only the areas where there may be potential substitutes (non-olive-growing lands; i.e. "Substitute area" in density-based index formulae).
} 


$$
\begin{aligned}
& D E N S \_I N V 2=100 \times \sum_{a=1}^{a=A} \frac{1}{d_{a}^{2}} \times \frac{\text { Olive_area }_{a}}{\text { Substitute_area }} \\
& D E N S \_I N V L N=\sum_{\mathrm{a}=1}^{a=A} \frac{1}{\ln d_{a}} \times \frac{\text { Olive_area }_{a}}{\text { Substitute_area }}
\end{aligned}
$$

In sum, all these density-based indexes are obtained similarly to the area-based ones, but considering the olive grove density (i.e. the ratio Olive_area $a_{a}$ Substitute_area $a_{a}$ ) instead of just the olive area. In this way, the existence of non-randomly distributed substitute sites is accounted for. Thus, the larger the olive area and the closer it is, or the smaller the substitute area and the farther away it is, the higher the index value. To illustrate this, Fig. 4 shows two examples of the calculation of the indexes; one for Lucena (Cordova province), with a large presence of nearby olive groves, and the other for San Fernando (Cádiz province), located far away from olive grove areas.

In order to test the initial hypothesis of the superiority of the area- and density-based approaches compared to traditional distance-based models, a standard distance-decay function was also included into the analysis. To do this, the distance between each respondent's residence and the nearest olive grove parcel was calculated, using GIS techniques.

\subsection{Choice experiment approach: Attributes, levels and questionnaire design}

Stated-preference approaches are the most suitable valuation methods to measure the well-being people obtain from the consumption of ES provided by agricultural systems, enabling estimates of the WTP, including both use and non-use values. Thus, the contingent valuation method (CVM) and discrete choice experiments (DCE) have been widely used for this purpose. However, considering that agricultural systems usually supply a bundle of ES, DCE has emerged as the preferred approach (Madureira et al., 2013).

Since olives groves are indeed characterised by the joint provision of ES, we have considered DCE the most suitable valuation approach, as in many previous studies (e.g. Colombo, Calatrava-Requena and Hanley, 2006; Rodríguez-Entrena et al., 2012). In order to implement this valuation method, we select four attributes: three non-monetary and one monetary (see Table 1). The first three relate to the main ES provided by Andalusian olive groves, namely carbon sequestration, soil conservation and biodiversity. These main ES were selected on the basis of a literature review, interviews with experts (both inside and outside academia) and a focus group. For these non-monetary attributes, moderate and significant improvements in their provision levels were defined also based on literature review and experts' opinion. To facilitate the communication of these improvements to the respondents, proxy variables were defined for each attribute. For example, for carbon sequestration, the reduction 
in emissions measured in millions of tons of $\mathrm{CO}_{2}$ was presented as "emission reduction equivalent to the emissions of a city of X inhabitants". The final selection of non-monetary attribute levels was validated in the abovementioned focus group. The monetary attribute was defined as an annual increase in income tax during a 20-year period and levels were selected on the basis of a pre-test survey consisting of open-ended CVM questions for moderate and significant improvements in the three non-monetary attributes considered. The interested reader can consult Rodríguez-Entrena, Espinosa-Goded and Barreiro-Hurlé (2014) for detailed information about how these levels were defined and translated into the proxy variables used.

Table 1. Attributes, levels and proxy variables used in the choice set design

\begin{tabular}{|c|c|c|c|}
\hline Attribute & Technical variable & Proxy variable & Levels \\
\hline $\begin{array}{l}\mathrm{CO}_{2} \\
\text { sequestration }\end{array}$ & $\begin{array}{l}\mathrm{CO}_{2} \text { sequestered } \\
\text { annually in olive groves } \\
\text { in Andalusia }\end{array}$ & $\begin{array}{l}\text { Emission reduction } \\
\text { equivalent to the } \\
\text { emissions of a city } \\
\text { of... }\end{array}$ & $\begin{array}{l}\text { Status quo: } 300,000 \text { inhabitants } \\
\text { Moderate improvement [CSEQ500]: 500,000 inhabitants } \\
\text { Significant improvement [CSEQ700]: 700,000 inhabitants }\end{array}$ \\
\hline $\begin{array}{l}\text { Soil } \\
\text { conservation }\end{array}$ & $\begin{array}{l}\text { Annual reduction of soil } \\
\text { erosion rates in olive } \\
\text { groves in Andalusia }\end{array}$ & $\begin{array}{l}\text { Soil erosion in olive } \\
\text { grove area } \\
\text { equivalent to... }\end{array}$ & $\begin{array}{l}\text { Status quo: } 30 \text { Olympic stadiums } \\
\text { Moderate improvement [SOIL16]: } 16 \text { Olympic stadiums } \\
\text { Significant improvement [SOIL2]: } 2 \text { Olympic stadiums }\end{array}$ \\
\hline Biodiversity & $\begin{array}{l}\text { Increase in the number } \\
\text { of bird species in olive } \\
\text { groves in Andalusia }\end{array}$ & $\begin{array}{l}\text { Average number of } \\
\text { different bird species } \\
\text { per hectare of... }\end{array}$ & $\begin{array}{l}\text { Status quo: } 10 \text { bird species } \\
\text { Moderate improvement [BIOD15]: } 15 \text { bird species } \\
\text { Significant improvement [BIOD20]: } 20 \text { bird species }\end{array}$ \\
\hline Payment & $\begin{array}{l}\text { Annual willingness to } \\
\text { pay for the next } 20 \\
\text { years }\end{array}$ & $\begin{array}{l}\text { Annual increase in } \\
\text { taxes during the next } \\
20 \text { years of... }\end{array}$ & $\begin{array}{l}\text { Status quo: } 0 € / \text { year } \\
\text { Level 1: } 15 € / \text { year } \\
\text { Level 2: } 30 € / \text { year } \\
\text { Level 3: } 45 € / \text { year }\end{array}$ \\
\hline
\end{tabular}

Source: Rodríguez-Entrena, Espinosa-Goded and Barreiro-Hurlé (2014).

Before being presented with the sequence of choice cards, the interviewees were informed of the current level of provisioning ES provided by olive groves in Andalusia and the potential improvement through changes in farm management to be implemented under a comprehensive management plan for Andalusian olive groves. The interviewees were informed through a combination of graphic and written information about the specific characteristics of the programme implementation (ES improvements, duration, coverage, etc.), as well as about the financing of the programme (i.e. a 20year tax as payment vehicle). To avoid hypothetical bias, respondents were reminded of their budget constraints and the existence of substitute environmental programmes, and a "cheap talk" was also included in the interview (Cummings and Taylor, 1999).

Additionally, a follow-up question was designed to delve into the reasons for respondents' unwillingness to financially support the programme, distinguishing protest responses from real zeros. 
The questionnaire ended with a set of questions related to the socio-economic characteristics of the respondents, as well as their attitudes toward the ES under analysis.

Interested readers can find an English version of the questionnaire and the information used to explain the DCE in the supplementary material for the paper.

\subsection{Econometric specification}

To analyse the choices between alternative programmes of ES provision, random parameter logit specifications (RPL) with an error component were used. Among the advantages of using RPL models, it is worth highlighting its ability to deal with preference heterogeneity allowing for random taste variation, unrestricted substitution patterns and correlation in unobserved factors (Train, 2003; Hensher et al., 2005). The error component RPL specification (EC_RPL) usually outperforms the standard RPL one by including an additional term in the utility function capturing the error variance common to non-status quo (SQ) alternatives (Scarpa, Ferrini and Willis, 2005). This model has already been successfully used in different analyses of this type (e.g. Espinosa-Goded, Barreiro-Hurlé and Ruto, 2010; Villanueva et al., 2015b), justifying its use for this purpose.

In the EC_RPL, the utility function associated with each alternative is expressed as follows:

$$
\begin{gathered}
U_{A l t A}=\beta^{\prime} \chi+\beta_{s}^{\prime} \chi+\vartheta+\varepsilon \\
U_{A l t B}=\beta^{\prime} \chi+\beta_{s}^{\prime} \chi+\vartheta+\varepsilon \\
U_{S Q}=A S C_{S Q}+\beta^{\prime} \chi+\beta_{s}^{\prime} \chi+\gamma S+\varepsilon
\end{gathered}
$$

where $A S C_{S Q}$ is the alternative-specific constant for the SQ option, $\chi$ stands for a vector representing the attributes, $\theta$ is the additional error component (distributed with $N\left(0, \sigma^{2}\right)$ ) and $\varepsilon$ is the random error term, which is assumed to be identically and independently distributed (iid) and related to the choice probability with a Gumbel distributed error term. The vector of coefficients $(\beta)$ reflects individual preferences which, given that these are allowed to vary across individuals, is randomly distributed in the population following a density function $f\left(\beta_{n} \mid \vartheta\right)$, where $\vartheta$ represents the distribution parameters. $\beta_{s}$ represents heterogeneity that can be explained by individual characteristics. $\gamma S$ captures heterogeneity in preferences for the SQ option explained by a set of individual characteristics (with $S$ representing the vector of characteristics and $y$ the parameters to be estimated). Choices are modelled following a panel structure, thus with the integer probability involving a product of logit formulas. The joint probability of respondent $n$ choosing alternative $i$ in each of the $T$ choice situations is given by:

$$
P[t(n)]=\int_{\beta} \int_{\eta} \prod_{t=1}^{T} \frac{\exp \left(\lambda\left(\beta_{n}^{\prime} \chi_{t i n}+\vartheta\right)\right)}{\sum_{j \subset A_{t}} \exp \left(\lambda\left(\beta_{n}^{\prime} \chi_{t j n}+\vartheta\right)\right)} f\left(\beta_{n} \mid \theta\right) \varphi\left(0, \sigma^{2}\right) d \beta d \vartheta
$$


where $A_{t}=(A / t A, A$ lt $B, S Q)$ is the choice set, $\lambda$ is a scale parameter, $f\left(B_{n} \mid \vartheta\right)$ is the density of the attributes random parameters and $\varphi(\cdot)$ is the normal density of the error component $(\theta)$ which equals zero when $j=\mathrm{SQ}$. This integral does not have a closed form so is approximated using simulation methods (Train, 2003). Here, models were estimated using 1000 Halton draws. All attributes were assumed to follow a normal distribution, except for the monetary attribute, which is assumed to follow a constrained triangular distribution.

Three types of EC_RPL models were used in the analysis: one without considering any spatial index (Base Model), one interacting the spatial index considered in each model with the monetary attribute (Spatial Model 1) and one interacting the spatial index with all the attributes (Spatial Model 2) ${ }^{7}$. The last two models are used to show the improvements in model fit achieved by incorporating spatial heterogeneity, while the first one serves as a benchmark. For each of these two models, the different types of indexes (area- and density-based) described in Section 3.2 were used as sources of observed heterogeneity. In addition, as mentioned above, a distance-based approach based on the inverse of the minimum distance to the olive groves areas (DIST_INV) was included in these two models in order to test the hypothesis that the proposed area- and density-based approaches outperform the distancebased models ${ }^{8}$. To test for differences in goodness-of-fit of alternative models, the log-likelihood ratio test was used for nested specifications and the Vuong test for non-nested specifications (Vuong, $1989)^{9}$.

\subsection{Data gathering: experimental design and sample selection}

Respondents were offered three options (alternatives) of ES outputs, one of which represents the status quo situation without additional payment. We estimated an optimal-in-difference fractional factorial design following the methodological proposal of Street and Burgess (2007), from which a total

\footnotetext{
${ }^{7}$ Models with uncorrelated random parameters were used too. Following Mariel and Meyerhoff (2018), EC_RPL solutions with correlated random parameters were also explored, showing very minor improvements in model fit at the cost of a remarkable increase in the number of parameters. Given the higher complexity and low gains produced by these models, together with the fact that the results regarding the spatial analysis and interactions with ES attributes basically remain the same as for the EC_RPL models with uncorrelated random parameters, we decided not to report them and make them available on request. In any case, we agree with these authors on the convenience of exploring this type of solutions, especially when the number of parameters does not increase too much (e.g. when linear specifications are used).

${ }^{8}$ Different approaches with regard to the distance-decay function have been tested (including interaction with ES and payment parameters); the inverse of the distance (DIST_INV) is the one that achieves the best results in terms of pseudo- $R^{2}$ and $A I C / N$. These models are available on request.

${ }^{9}$ The Vuong test is a likelihood-ratio-based test which tests the null hypothesis that the expected value of the difference vector of log-likelihood ratios for competing models equals zero, indicating that there is no evidence of superior fit among alternative specifications. As the statistic estimated with the Vuong test follows a standard normal distribution, the critical value of 1.96 corresponds to a $5 \%$ level of significance, which means that if the test exceeds that threshold in absolute values, there is evidence of the existence of a superior specification.
} 
of 324 choice sets were obtained (the overall number of potential choice sets would be $\left.\left(3^{3} \times 4\right)^{2}\right)$. These 324 choice sets were randomly assigned to 36 choice blocks with 9 choice sets each. During the pilot interviews, no saturation effect due to this number of choices was detected (Rodríguez-Entrena, Espinosa-Goded and Barreiro-Hurlé, 2014).

Regarding the study of spatial heterogeneity of values for sparsely-located ES, random sampling is unlikely to provide a geographically representative sample, for two reasons (Concu, 2007): first, response rates in surveys decline with distance; and second, populations are rarely uniformly distributed over space, with more densely-populated geographical areas likely to be over-represented. Instead, for this investigation, where the target population analysed to assess the proposed improvement in the provision of ES was the Andalusian population aged 18 or over (6.54 million inhabitants), sample selection was carried out following a multi-stage cluster approach. The primary sample units (municipalities) were selected following a random procedure, considering their size (rural, intermediate or urban), whereas the final sample units (individuals) were selected by random routes, imposing gender and age quotas ${ }^{10}$. Moreover, in order to ensure that spatial heterogeneity could be estimated reliably, the sampling strategy implemented involved confirming that the sample drawn was also stratified according to the area and density indexes considered for the analysis (Schaafsma, 2015).

Fieldwork was carried out between February and April 2011 by a market research company. The research team trained and monitored the interviewers in the initial stage of the questionnaire implementation to ensure that it was correctly administered.

The final sample consisted of 476 individuals. Table 2 shows the sample distribution in two of the spatial indexes employed. As can be seen, the sample is evenly distributed, so it can be assumed to be suitable for spatial analysis.

Table 2. Sample distribution in spatial indexes

\begin{tabular}{cccc}
\hline AREA_INV & Number of interviews & DENS_INV & Number of interviews \\
\hline$<1.0$ & 124 & $<0.5$ & 126 \\
$1.0-2.0$ & 178 & $0.5-1.0$ & 178 \\
$>2.0$ & 174 & $>1.0$ & 172 \\
\hline
\end{tabular}

${ }^{10}$ Non-significant differences with official statistics have been confirmed using $\chi^{2}$ tests for gender, age, type of residential area (urban, rural and intermediate) and education level. For income, there is no available information to test for differences, although it can be noted that the gross domestic product per capita in Andalusia is $€ 1463 /$ month. All this confirms the sample representativeness for the population considered. 


\section{Results and discussion}

\subsection{Alternative approaches for spatial analysis}

Table 3 shows the main goodness-of-fit statistics (Pseudo- $R^{2}$ and $A I C / N$ ) for spatial models 1 and 2 and the seven spatial indexes considered, as well as those for the Base Model (detailed results will be described in the next section). Table 4 shows the comparison in terms of goodness-of-fit between the Base Model and Spatial Model 1, and between Spatial Model 1 and Spatial Model 2, using the likelihood ratio (LR) test. While models show a high goodness-of-fit regardless of the specification (see Table 3 ), the results shown in Table 4 suggest that modelling can be significantly improved (at the 1\% level) by incorporating spatial indexes as interaction terms. This improvement is observed for the interaction with the monetary attribute alone, and even more so for the interaction with all the attributes, for any of the spatial indexes proposed except the DIST_INV index. In the case of the latter index, the introduction of the interaction with the ES attributes (Spatial Model 2) does not improve Spatial Model 1.

Table 3. Model fit statistics with the seven spatial indexes

\begin{tabular}{|c|c|c|c|c|}
\hline & \multicolumn{2}{|c|}{$\begin{array}{c}\text { Spatial Model } 1 \\
\text { (payment interaction) }\end{array}$} & \multicolumn{2}{|c|}{$\begin{array}{c}\text { Spatial Model } 2 \\
\text { (payment and ES interactions) }\end{array}$} \\
\hline & Pseudo-R ${ }^{2}$ & $\mathrm{AlC} / \mathrm{N}$ & Pseudo-R ${ }^{2}$ & $\mathrm{AlC} / \mathrm{N}$ \\
\hline DIST_INV & 0.558 & 0.979 & 0.559 & 0.980 \\
\hline AREA_INV & 0.560 & 0.976 & 0.563 & 0.970 \\
\hline AREA_INV2 & 0.558 & 0.979 & 0.561 & 0.975 \\
\hline AREA_INVLN & 0.561 & 0.973 & 0.563 & 0.971 \\
\hline DENS_INV & 0.556 & 0.983 & 0.560 & 0.977 \\
\hline DENS_INV2 & 0.556 & 0.984 & 0.559 & 0.979 \\
\hline DENS_INVLN & 0.559 & 0.978 & 0.562 & 0.974 \\
\hline
\end{tabular}

Note: Base Model (without any spatial index): Pseudo- $\mathrm{R}^{2}: 0.554 ; \mathrm{AIC} / \mathrm{N}: 0.988$.

Table 4. Results of the likelihood ratio test for nested models

\begin{tabular}{lcccc}
\hline & \multicolumn{2}{c}{ Spatial Model 1 vs Base Model } & \multicolumn{2}{c}{ Spatial Model 2 vs Spatial Model 1 } \\
\cline { 2 - 5 } & LR statistic & Critical $X^{2}$ (DF) & LR statistic & Critical $X^{2}$ (DF) \\
\hline DIST_INV & $43.11^{* * *}$ & $5.99(2)$ & 6.63 & $12.59(6)$ \\
AREA_INV & $55.74^{* * *}$ & $5.99(2)$ & $36.34^{* * *}$ & $12.59(6)$ \\
AREA_INV2 & $40.54^{* * *}$ & $5.99(2)$ & $28.96^{* * *}$ & $12.59(6)$ \\
AREA_INVLN & $65.96^{* * *}$ & $5.99(2)$ & $21.32^{* *}$ & $12.59(6)$ \\
DENS_INV & $22.95^{* * *}$ & $5.99(2)$ & $38.85^{* * *}$ & $12.59(6)$ \\
DENS_INV2 & $21.12^{* * *}$ & $5.99(2)$ & $32.11^{* * *}$ & $12.59(6)$ \\
DENS_INVLN & $45.63^{* * *}$ & $5.99(2)$ & $28.53^{* * *}$ & $12.59(6)$ \\
\hline
\end{tabular}

${ }^{* * * * * *}$ denote significance at $0.1 \%$ and $1 \%$ level, respectively. 
As shown in Table 3, the models based on the different indexes have similar values in terms of goodness-of-fit statistics, and there are no notable differences that would allow conclusive results to be drawn from their comparison. However, focusing on the distance discounting factor of the best specification (i.e. Spatial Model 2), and comparing the goodness-of-fit statistics for all distance discounting factors (INV, INV2 and INVLN) it could be argued that the area-based approach slightly outperforms the density-based approach (slightly higher values for Pseudo- $R^{2}$ and lower values for $\mathrm{AIC} / \mathrm{N}$ ), while the approach based exclusively on distance seems to be slightly worse than the other two. Moreover, it could be contended that for both area-based and density-based approaches, the models based on the inverse of the squared distance (AREA_INV2 and DENS_INV2) perform slightly worse than the models using inverse distance (i.e. AREA_INV and DENS_INV) and the logarithmic transformation of the distance (AREA_INVLN and DENS_INVLN).

In order to test for significant differences in the goodness-of-fit statistics, we carried out the Vuong test for the Spatial Model 2 specification (see Table 5). As can be seen, the only model that shows significantly better performance when compared to the distance-based model (DIST_INV) is that based on the combination of the area and the inverse of the distance (i.e. the AREA_INV index). This areabased model also outperforms all the other area-based and all the density-based approaches. Additionally, significant differences among the density-based models were found: the model based on the inverse of the distance (DENS_INV) is better than that based on the inverse of the squared distance (DENS_INV2), while the inverse of the logarithmic transformation of the distance (DENS_INVLN) performs better than the other two.

Table 5. Results of the Vuong test for non-nested models (considering Spatial Model 2 specification only)

\begin{tabular}{|c|c|c|c|c|c|c|c|}
\hline & DIST_INV & AREA_INV & AREA_INV2 & AREA_INVLN & DENS_INV & DENS_INV2 & DENS_INVLN \\
\hline DIST_INV & --- & & & & & & \\
\hline AREA_INV & $3.65^{* * *}$ & --- & & & & & \\
\hline AREA_INV2 & -0.27 & $-5.08^{* * *}$ & --- & & & & \\
\hline AREA_INVLN & 0.66 & $-3.67^{* * *}$ & 0.91 & --- & & & \\
\hline DENS_INV & 0.02 & $-3.56^{* * *}$ & 0.32 & -0.72 & --- & & \\
\hline DENS_INV2 & -0.45 & $-3.67^{* * *}$ & -0.40 & -1.21 & $-3.28^{* *}$ & --- & \\
\hline DENS_INVLN & 0.85 & $-2.93^{* *}$ & 1.46 & 0.25 & $2.44^{* *}$ & $3.11^{* *}$ & --- \\
\hline
\end{tabular}

${ }^{* * *} ;{ }^{* *}$ denote significance at $0.1 \%$ and $1 \%$ level, respectively. A negative (positive) sign means that the model in the column (row) outperforms the model in the row (column).

The results partly support the hypothesis posed at the end of Section 2 regarding the best approach for spatial analysis, as the area-based approach shows an improvement over the traditional distancebased one. Yet the hypothesis of the superiority of density-based over distance-based and area-based approaches should be rejected, as none of the density-based models outperforms either the area- 
based or distance-based approaches. This counterintuitive result could, however, be explained by the implicit assumption that all the other land uses apart from olive growing (substitute sites) have equal levels of ES provision. Clearly, our results from comparing these three spatial approaches point to the need for further research focusing on the heterogeneity of ES provision of substitute sites and the development of new density-based indexes able to take account of different substitute sites (i.e. land uses) with distinct levels of ES provision.

Similarly, the result that the use of the inverse of the distance only yields better results for one of the approaches (i.e. AREA) should be taken with caution, and we should be wary of claiming the clear superiority of this spatial discounting factor over the others. In any case, these results suggest a less pronounced discounting effect than that found by De Valck et al. (2017), who report the use of the inverse of the squared distance as showing the best results. Very probably, the different characteristics of the case studies (an agricultural system in our case and the restoration of different natural sites in theirs, and the geographic context-Flanders/Andalusia, etc.) can explain this difference. Also, further empirical evidence is needed in order to reach firm conclusions about this topic.

Finally, some considerations with regard to the indexes should be pointed out. First, this investigation has only considered the region of Andalusia, as the analysis focused on Andalusian residents' preferences toward the provision of ES by Andalusian olive groves; as such, respondents stated preferences relating only to this agricultural system. In any case, the bulk of Spanish olive cultivation is concentrated in this region (62\% of the national olive area), with olive grove areas in neighbouring regions being much scarcer and more scattered. Taking this into account, we consider that this focus on Andalusia has not influenced the results related to the use of both area-based and density-based indexes.

Second, with regard to density-based indexes, the shape of the Andalusian region was superimposed over the annuli to obtain the "Substitute area" introduced in the denominator of these indexes. Thus, some of the annuli have been cut so that the area outside the Andalusian regional borders, including the maritime area, has been excluded from the calculations. We have confirmed that the inclusion of the area outside the Andalusian borders does not affect the final results of the models (models are available on request).

\subsection{Demand for ES provided by olive farming}

As has been pointed out in the previous section, the model based on the AREA_INV index has significantly better goodness-of-fit statistics than the equivalent models based on the other indexes. 
Therefore, we now present only the results regarding the demand for ES provided by olive farming yielded by the models based on AREA_INV ${ }^{11}$.

Table 6 shows the results of the Base Model and the two spatial models (Spatial Model 1 and 2 using AREA_INV index). As can be seen, all the main effect parameters are significant and have the expected sign (i.e. positive for the ES parameters and negative for the payment parameter). Their standard deviations are significant, except for moderate improvements in carbon sequestration and soil conservation (CSEQ500 and SOIL16, respectively), meaning that there is heterogeneity of preferences regarding the ES provided by olive growing. The error component is significant, indicating that it efficiently captures the 'status quo effect' (Scarpa, Ferrini and Willis, 2005). With regard to the spatial heterogeneity, the interaction of the spatial index with the payment parameter is significant and positive in both spatial models. This indicates that the benefits stemming from the ES increase with increasing values of the AREA_INV index. Therefore, this means that -ceteris paribus- the larger the olive grove area nearby (i.e. higher AREA_INV index), the higher the WTP for the ES provided by this agricultural ecosystem. As a result, the spatial effect on the demand for ES provided by olive groves is found to be significant, which corroborates results found in most of the previous studies (Schaafsma, 2015). Furthermore, when the spatial index is included, Spatial Model 2 shows three additional significant interaction parameters, namely those with CSEQ500, CSEQ700 and SOIL2, all of which are negative, implying an opposite effect to that explained above for the payment interaction. Indeed, these interactions indicate a lower intensity of preferences toward the provision of ES related to carbon sequestration and soil conservation when the nearby olive grove area is larger.

\footnotetext{
11 In any case, the results obtained using models that incorporate the other spatial indexes are very similar to those obtained from the AREA_INV model. These results are available on request.
} 
Table 6. Results of the EC_RPL models

\begin{tabular}{|c|c|c|c|c|c|c|}
\hline & \multicolumn{2}{|c|}{$\begin{array}{c}\text { Base Model } \\
\text { (no interactions) }\end{array}$} & \multicolumn{2}{|c|}{$\begin{array}{c}\text { Spatial Model } 1 \\
\text { (payment interaction) }\end{array}$} & \multicolumn{2}{|c|}{$\begin{array}{l}\text { Spatial Model } 2 \text { (payment } \\
\text { and ES interactions) }\end{array}$} \\
\hline & Coeff. & S.E. & Coeff. & S.E. & Coeff. & S.E. \\
\hline \multicolumn{7}{|l|}{ Parameter mean values } \\
\hline CSEQ500 & $1.438^{* * *}$ & 0.128 & $1.381^{* * *}$ & 0.125 & $2.624^{* * *}$ & 0.318 \\
\hline CSEQ700 & $2.474^{* * *}$ & 0.146 & $2.467^{* * *}$ & 0.139 & $3.995^{* * *}$ & 0.371 \\
\hline SOIL16 & $1.527^{* * *}$ & 0.124 & $1.506^{* * *}$ & 0.125 & $1.736^{* * *}$ & 0.342 \\
\hline SOIL2 & $2.476^{* * *}$ & 0.148 & $2.459^{* * *}$ & 0.152 & $3.287^{* * *}$ & 0.350 \\
\hline BIOD15 & $0.850^{* * *}$ & 0.117 & $0.852^{* * *}$ & 0.117 & $0.785^{*}$ & 0.328 \\
\hline BIOD20 & $1.027^{* * *}$ & 0.130 & $1.007^{* * *}$ & 0.124 & $0.892^{*}$ & 0.361 \\
\hline PAYMENT & $-0.250^{* * *}$ & 0.011 & $-0.339^{* * *}$ & 0.021 & $-0.355^{* * *}$ & 0.022 \\
\hline ASCSQ & $1.700^{* * *}$ & 0.315 & 0.401 & 0.691 & 1.433 & 0.809 \\
\hline \multicolumn{7}{|l|}{ Co-variables } \\
\hline CSEQ500xAREA_INV & & & & & $-0.644^{* * *}$ & 0.176 \\
\hline CSEQ700xAREA_INV & & & & & $-0.790^{* * *}$ & 0.187 \\
\hline SOIL16XAREA_INV & & & & & -0.076 & 0.180 \\
\hline SOIL2XAREA_INV & & & & & $-0.401^{*}$ & 0.169 \\
\hline BIOD15XAREA_INV & & & & & 0.035 & 0.166 \\
\hline BIOD20xAREA_INV & & & & & 0.086 & 0.186 \\
\hline PAYMENTXAREA_INV & & & $0.054^{* * *}$ & 0.008 & $0.056^{* * *}$ & 0.010 \\
\hline ASCSQXAREA_INV & & & 0.590 & 0.311 & 0.100 & 0.393 \\
\hline \multicolumn{7}{|l|}{ Standard deviations } \\
\hline CSEQ500 & 0.171 & 0.514 & 0.091 & 0.752 & 0.058 & 0.646 \\
\hline CSEQ700 & $0.745^{* *}$ & 0.238 & $0.650^{*}$ & 0.274 & $0.850^{* * *}$ & 0.253 \\
\hline SOIL16 & 0.408 & 0.317 & 0.412 & 0.335 & 0.498 & 0.309 \\
\hline SOIL2 & $0.949^{* * *}$ & 0.187 & $0.820^{* * *}$ & 0.196 & $0.993^{* * *}$ & 0.221 \\
\hline BIOD15 & $0.616^{* *}$ & 0.222 & 0.504 & 0.271 & $0.595^{*}$ & 0.245 \\
\hline BIOD20 & $1.048^{* * *}$ & 0.159 & $0.931^{* * *}$ & 0.179 & $1.040^{* * *}$ & 0.206 \\
\hline PAYMENT & $0.250^{* * *}$ & 0.011 & $0.339^{* * *}$ & 0.021 & $0.355^{* * *}$ & 0.022 \\
\hline Error component & $-4.939^{* * *}$ & 0.359 & $4.817^{* * *}$ & 0.355 & $5.163^{* * *}$ & 0.401 \\
\hline \multicolumn{7}{|l|}{ Model fit statistics } \\
\hline Log-likelihood (b) & -2099.54 & & -2071.67 & & -2053.50 & \\
\hline Log-likelihood (b0) & -4704.26 & & -4704.26 & & -4704.26 & \\
\hline Pseudo- $R^{2}$ & 0.554 & & 0.560 & & 0.563 & \\
\hline $\mathrm{N}$ & 4282 & & 4282 & & 4282 & \\
\hline $\mathrm{AIC} / \mathrm{N}$ & 0.988 & & 0.976 & & 0.970 & \\
\hline
\end{tabular}

${ }^{* * *} ;{ }^{* * *}$ i denote significance at $0.1 \%, 1 \%$ and $5 \%$ level, respectively.

From the results of Spatial Model 2, the WTP for the ES provided by Andalusian olive growing is estimated using Hanemann's (1984) methodological approach. Fig. 5 represents the estimates of WTP for moderate (Fig. 5a) and significant improvements (Fig. 5b) in each and all of the ES considered in function of the AREA_INV index. 


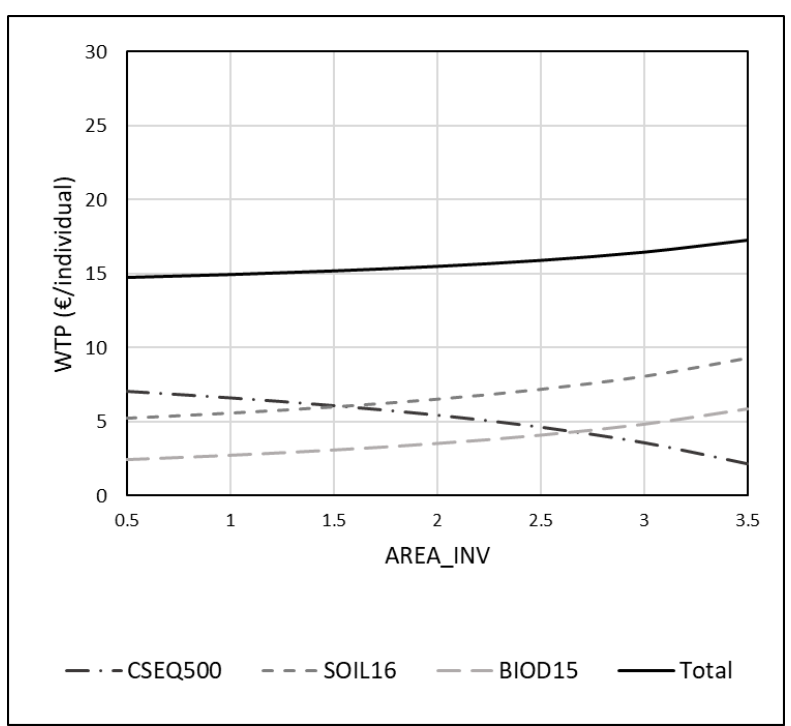

5a. Moderate improvement

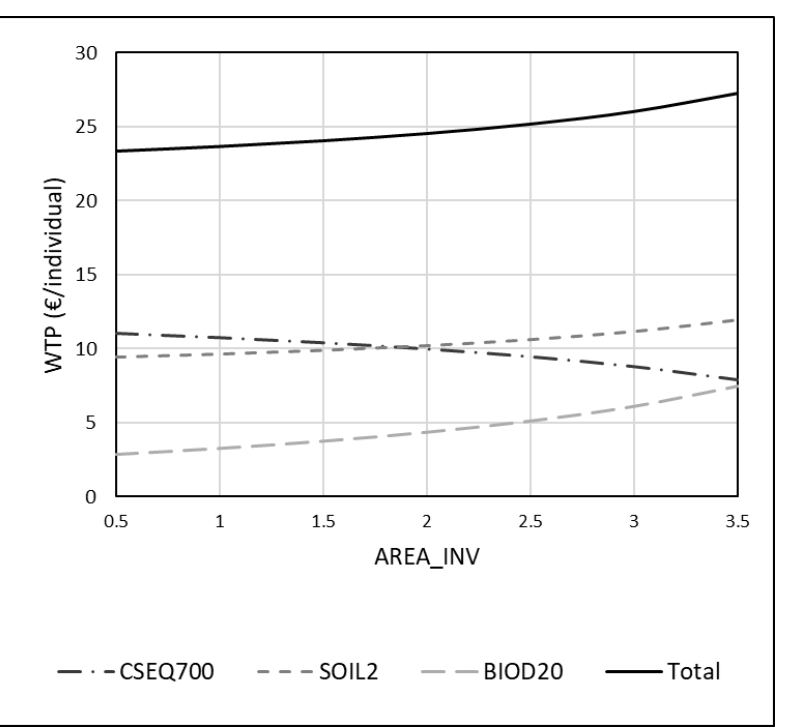

5b. Significant improvement

Fig. 5. Relationship between the WTP and the AREA_INV Index for moderate and significant improvements in the 3 attributes considered.

As shown in these figures, the total WTP (jointly considering the three ES under analysis) increases with increasing values of the index for both moderate and significant improvements, although the ranges of variation are narrow. The small differences among the total WTP values in different locations could be explained by the high importance of the olive groves for land use management in Andalusia. This sector is prevalent throughout the whole region, representing an iconic provider of ES, and is often deeply rooted in the Andalusian people's sense of identity. Therefore, the fact that the olive sector is commonly considered a matter of regional importance may explain why we find limited differences in the total WTP for the provision of the ES linked to this agroecosystem. However, when observing the curves for each of the ES separately, different patterns emerge, showing increasing trends for biodiversity and soil conservation and a decreasing trend for carbon sequestration. These trends show the combined results of two effects: the positive relationship between AREA_INV and the payment parameter and the negative relationship between AREA_INV and CSEQ500, CSEQ700, SOIL16 and SOIL2. For example, for carbon sequestration, the effect of the interactions of AREA_INV with the parameters (CSEQ500 and CSEQ700) is large enough to prevail over the interaction with the payment. Conversely, in the case of soil conservation, the effect of the interaction with the monetary parameter (lowering the disutility of the payment) prevails over the interaction with the ES parameter (especially for moderate improvements), thus showing such a positive trend as a result. In the case of biodiversity, the positive trend seems to be more remarkable for both moderate and significant improvements, especially since no negative interaction term is present.

All this suggests that the spatial effects depend on the kind of ES considered. This seems to be related to the type of value attached to the service (use and non-use values). Accordingly, in locations 
near to large olive groves (i.e. associated with a high value of the AREA_INV index), individuals show a preference for the ES with more prominent use value (biodiversity and soil conservation), whereas their WTP for carbon sequestration is lower. On the contrary, those who live farther away from olive grove areas (i.e. associated with a low value of the AREA_INV index) show a higher preference for carbon sequestration than for the ES with higher use value, although on aggregate their WTP for the bundle of the three ES considered is lower. The rationale behind this is that ES with benefits of a notable use value (such as biodiversity or soil conservation, ES of a primarily local nature) show greater spatial discounting than those that have a primarily non-use value (such as carbon sequestration, an ES which is mainly global in scale). Although different discounting rates for use and non-use values have been pointed out previously (e.g. Hanley, Schläpfer and Spurgeon, 2003; Schaafsma, Brouwer and Rose, 2012; Jørgensen et al., 2013; Schaafsma et al., 2013), to the authors' knowledge this is the first study to report such a finding for different types of services as well as for scattered environmental sites.

The heterogeneous distribution of the WTP for different ES reveals spatial patterns that should be considered in policy analysis. The fact that the people living near olive grove areas are more willing to pay for ES such as biodiversity and soil conservation, whereas the population living farther away prefers carbon sequestration, indicates the existence of different economic jurisdictions for such ES. Thus, local (or regional) jurisdiction should be considered for ES with prominent use value and a transnational (or global) jurisdiction for the case of ES with a prominent non-use value. These different economic jurisdictions have relevant implications regarding the design, implementation and financing of the policies related to the provision of ES by agroecosystems.

\section{Conclusions}

Previous literature demonstrates the existence of spatial heterogeneity in the demand for ES, especially by showing spatial discounting (namely, distance-decay) and the effect of substitute sites. Our study further contributes by analysing different ways of modelling these two effects and applying them to a scattered ecosystem which provides various ES. For this purpose, novel spatial approaches using different discounting factors (inverse of the distance, inverse of the squared distance and inverse of the logarithm of the distance) and incorporating the presence of substitutes (density-based vs. areabased indexes) have been tested for the first time using an agroecosystem (olive groves in Andalusia, southern Spain) as a case study.

The results show that the introduction of any of these spatial indexes significantly improves the fit of the valuation models. As such, they successfully incorporate spatial heterogeneity into the analysis of the demand for ES. Although the results suggest slight differences among indexes with different 
discounting factors and between distance-, density- and area-based indexes, the discounting factor consisting of the inverse of the distance and the index based on area yield the best outcome. Yet these results clearly call for further analysis to confirm the extent to which the use of each-the inverse of the distance and the area-based approach-should be recommended when accounting for spatial heterogeneity in the benefits associated with ES provided by scattered ecosystems. In addition, our results showing no differences between distance-based and density-based approaches point to the need for future research focusing on the development of new density-based indexes that effectively capture the heterogeneity of the ES provision of substitute sites. In particular, a specific avenue of research may focus on using density-based indexes in which different substitute sites (i.e. in terms of land uses) are weighted according to their levels of ES provision.

Besides the use of different spatial indexes, other noteworthy findings are related to the differences in the spatial heterogeneity of benefits derived from the diverse ES provided by the agroecosystem under study. On the one hand, results show the positive relationship between the WTP for biodiversity and soil conservation and the spatial index; that is, the greater the presence of nearby olive groves, the greater the demand for the provision of these ES. On the other, the results show the opposite relationship for carbon sequestration. These differences may well be related to the different use or non-use values of the ES analysed, as use values prevail with both biodiversity and soil conservation, whereas for carbon sequestration non-use values are more prominent. Although previous studies have reported different spatial heterogeneity for use and non-use values, this is the first to illustrate this for different ES and using an agroecosystem as a case study. Given the lack of studies of this type focusing on agroecosystems, further analyses should confirm these findings.

These results have important implications for policy decision-making related to the provision of ES in agroecosystems, since they provide evidence of different economic jurisdictions for each ES, thus also suggesting the need for different political jurisdictions to manage the design, implementation and financing of appropriate policy instruments. For carbon sequestration, no positive spatial discounting in the demand for this ES has been found, implying the economic jurisdiction should be understood as extending beyond regional or national borders. Thus, for this ES, the results provide reasonable support for the idea that related policies should be designed by European institutions, based on their international commitments, as the impact of such policies would be perceived by the wider population at this large scale. On the contrary, for the cases of biodiversity and soil conservation, a positive relationship has been shown between WTP and the spatial indexes (i.e. economic jurisdiction at local or regional levels); as such, the results indicate that regional or local governments should design, implement and finance related policies, as subsequent improvements mainly benefit the local population. 
Finally, it is worth pointing out that although the characteristics of the ES with regard to use and non-use values have been suggested as a key factor for spatial discounting, more research is needed to confirm this hypothesis. This is particularly relevant in the case of ES such as biodiversity, for which it is not always clear whether use or non-use values are more prominent. A promising future contribution in this regard could be to analyse WTP for ES while controlling for whether individuals directly benefit from ES provision (users) or not (non-users).

Moreover, although it has usually been assumed in the literature that spatial discounting patterns are only affected by spatial factors (e.g. distance, area, density), it is worth pointing out that a promising avenue for future research relates to testing if these discounting patterns could be individual- and/or ES-specific. Thus, further studies may explore the extent to which these patterns are also related to households' socioeconomic characteristics or linked to features defining different environmental sites.

\section{Supplementary data}

Supplementary data are available at European Review of Agricultural Economics online.

\section{Acknowledgments}

The authors are particularly grateful to the three anonymous reviewers for their very helpful comments and suggestions on previous versions of the paper.

\section{References}

Abildtrup, J., Garcia, S., Olsen, S. B. and Stenger, A. (2013). Spatial preference heterogeneity in forest recreation. Ecological Economics 92: 67-77.

Agee, M. D. and Crocker, T. D. (2010). Directional heterogeneity of environmental disamenities: the impact of crematory operations on adjacent residential values. Applied Economics 42: 1735-1745

Aguilera, E., Guzmán, G. and Alonso, A. (2014). Greenhouse gas emissions from conventional and organic cropping systems in Spain. II. Fruit tree orchards. Agronomy for Sustainable Development 35: 725-737.

Bateman, I. J., Day, B. H., Georgiou, S. and Lake, I. (2006). The aggregation of environmental benefit values: Welfare measures, distance decay and total WTP. Ecological Economics 60: 450-460.

Brody, S. D., Highfield, W. and Alston, L. (2004). Does location matter? Measuring environmental perceptions of creeks in two San Antonio watersheds. Environment and Behavior 36: 229-250.

Brouwer, R. and Slangen, L. H. G. (1998). Contingent valuation of the public benefits of agricultural wildlife management: The case of Dutchpeat meadow land. European Review of Agricultural Economics 25: 5372 
Brouwer, R., Martin-Ortega, J. and Berbel, J. (2010). Spatial preference heterogeneity: A choice experiment. Land Economics 86: 552-568.

Budziński, W., Campbell, D., Czajkowski, M., Demšar, U. and Hanley, N. (2018). Using geographically weighted choice models to account for the spatial heterogeneity of preferences. Journal of Agricultural Economics 69: 606-626.

Cameron, T. A. (2006). Directional heterogeneity in distance profiles in hedonic property value models. Journal of Environmental Economics and Management 51: 26-45.

Campbell, D., Scarpa, R. and Hutchinson, W. G. (2008). Assessing the spatial dependence of welfare estimates obtained from discrete choice experiments. Letters in Spatial and Resource Sciences 1: 117-126.

Campbell, D., Hutchinson, W. G. and Scarpa, R. (2009). Using choice experiments to explore the spatial distribution of willingness to pay for rural landscape improvements. Environment and Planning A 41: 97111.

Colombo, S., Calatrava-Requena, J. and Hanley, N. (2006). Analysing the social benefits of soil conservation measures using stated preference methods. Ecological Economics 58: 850-861.

Colombo, S. and Hanley, N. (2008). How can we reduce the errors from benefits transfer? An investigation using the choice experiment method. Land Economics 84: 128-147.

Colombo, S. and Camacho-Castillo, J. (2014). Caracterización del olivar de montaña andaluz para la implementación de los Contratos Territoriales de Zona Rural. Información Técnica Económica Agraria 110: 282-299.

Concu, G. B. (2007). Investigating distance effects on environmental values: a choice modelling approach. Australian Journal of Agricultural and Resource Economics 51: 175-194.

Cummings, R. G. and Taylor, L. O. (1999). Unbiased value estimates for environmental goods: A cheap talk design for the contingent valuation method. American Economic Review 89: 649-665.

Czajkowski, M., Budziński, W., Campbell, D., Giergiczny, M. and Hanley, N. (2017). Spatial heterogeneity of willingness to pay for forest management. Environmental and Resource Economics 68: 705-727.

De Valck, J., Broekx, S., Liekens, I., Aertsens, J. and Vranken, L. (2017). Testing the influence of substitute sites in nature valuation by using spatial discounting factors. Environmental and Resource Economics 66: 17-43.

Espinosa-Goded, M., Barreiro-Hurlé, J. and Ruto, E. (2010). What do farmers want from agri-environmental scheme design? A choice experiment approach. Journal of Agricultural Economics 61: 259-273.

Ferraro, P. J., Lawlor, K., Mullan, K. L. and Pattanayak, S. K. (2012). Forest figures: Ecosystem services valuation and policy evaluation in developing countries. Review of Environmental Economics and Policy 6: 20-44.

Gómez-Limón, J. A., Picazo-Tadeo, A. J. and Reig-Martínez, E. (2012). Eco-efficiency assessment of olive farms in Andalusia. Land Use Policy 29: 395-406.

Gómez Calero, J. A., Sobrinho, T. A., Giráldez, J. V. and Fereres, E. (2009). Soil management effects on runoff, erosion and soil properties in an olive grove of Southern Spain. Soil and Tillage Research 102: 5-13.

Haab, T. C. and Hicks, R. L. (1997). Accounting for choice set endogeneity in random utility models of recreation demand. Journal of Environmental Economics and Management 34: 127-147. 
Hanemann, W. M. (1984). Welfare evaluations in contingent valuation experiments with discrete responses. American Journal of Agricultural Economics 66: 332-341.

Hanley, N., Schläpfer, F. and Spurgeon, J. (2003). Aggregating the benefits of environmental improvements: distance-decay functions for use and non-use values. Journal of Environmental Management 68: 297-304.

Hensher, D., Hanley, A., Rose, J. M. and Greene, W. H. (2005). Applied Choice Analysis: A Primer. Cambridge, UK: Cambridge University Press.

Holland, B. M. and Johnston, R. J. (2017). Optimized quantity-within-distance models of spatial welfare heterogeneity. Journal of Environmental Economics and Management 85: 110-129.

Johnston, R. J. and Ramachandran, M. (2014). Modeling spatial patchiness and hot spots in stated preference willingness to pay. Environmental and Resource Economics 59: 363-387.

Johnston, R. J., Jarvis, D., Wallmo, K. and Lew, D. K. (2015). Multiscale spatial pattern in nonuse willingness to pay: Applications to threatened and endangered marine species. Land Economics 91: 739-761.

Johnston, R. J., Besedin, E. Y. and Holland, B. M. (2019). Modeling distance decay within valuation meta-analysis. Environmental and Resource Economics 72: 657-690.

Jørgensen, S. L., Olsen, S. B., Ladenburg, J., Martinsen, L., Svenningsen, S. R. and Hasler, B. (2013). Spatially induced disparities in users' and non-users' WTP for water quality improvements-Testing the effect of multiple substitutes and distance decay. Ecological Economics 92: 58-66.

Lizin, S., Brouwer, R., Liekens, I. and Broeckx, S. (2016). Accounting for substitution and spatial heterogeneity in a labelled choice experiment. Journal of Environmental Management 181: 289-297.

Loomis, J. B. (2000). Vertically summing public good demand curves: An empirical comparison of economic versus political jurisdictions. Land Economics 76: 312-321.

Madureira, L., Santos, J. L., Ferreira, A. and Guimarães, H. (2013). Feasibility Study on the Valuation of Public Goods and Externalities in EU Agriculture. Luxembourg: Publications Office of the European Union.

Mariel, P. and Meyerhoff, J. (2018). A more flexible model or simply more effort? On the use of correlated random parameters in applied choice studies. Ecological Economics 154: 419-429.

Meyerhoff, J., Boeri, M. and Hartje, V. (2014). The value of water quality improvements in the region BerlinBrandenburg as a function of distance and state residency. Water Resources and Economics 5: 49-66.

Nielsen, A. S. E., Lundhede, T. H. and Jacobsen, J. B. (2016). Local consequences of national policies - A spatial analysis of preferences for forest access reduction. Forest Policy and Economics 73: 68-77.

Pannell, D. J. (2008). Public benefits, private benefits, and policy mechanism choice for land-use change for environmental benefits. Land Economics 84: 225-240.

Paracchini, M. L., Petersen, J.-E., Hoogeveen, Y., Bamps, C., Burfield, I. and van Swaay, C. (2008). High Nature Value Farmland in Europe. An Estimate of the Distribution Patterns on the Basis of Land Cover and Biodiversity Data. Luxembourg: Office for Official Publications of the European Communities.

Pate, J. and Loomis, J. (1997). The effect of distance on willingness to pay values: A case study of wetlands and salmon in California. Ecological Economics 20: 199-207.

Perrings, C. and Hannon, B. (2001). An introduction to spatial discounting. Journal of Regional Science 41: 23-38. 
Poudyal, N. C., Hodges, D. G., Tonn, B. and Cho, S.-H. (2009). Valuing diversity and spatial pattern of open space plots in urban neighborhoods. Forest Policy and Economics 11: 194-201.

Rocamora-Montiel, B., Colombo, S. and Salazar-Ordóñez, M. (2014). Social attitudes in southern Spain to shape EU agricultural policy. Journal of Policy Modeling 36: 156-171.

Rocamora-Montiel, B., Glenk, K. and Colombo, S. (2014). Territorial management contracts as a tool to enhance the sustainability of sloping and mountainous olive orchards: Evidence from a case study in Southern Spain. Land Use Policy 41: 313-324.

Rodríguez-Entrena, M., Barreiro-Hurlé, J., Gómez-Limón, J. A., Espinosa-Goded, M. and Castro-Rodríguez, J. (2012). Evaluating the demand for carbon sequestration in olive grove soils as a strategy toward mitigating climate change. Journal of Environmental Management 112: 368-376.

Rodríguez-Entrena, M., Espinosa-Goded, M. and Barreiro-Hurlé, J. (2014). The role of ancillary benefits on the value of agricultural soils carbon sequestration programmes: Evidence from a latent class approach to Andalusian olive groves. Ecological Economics 99: 63-73.

Rogers, A. A., Kragt, M. E., Gibson, F. L., Burton, M. P., Petersen, E. H. and Pannell, D. J. (2015). Non-market valuation: Usage and impacts in environmental policy and management in Australia. Australian Journal of Agricultural and Resource Economics 59: 1-15.

Salazar-Ordóñez, M. and Sayadi, S. (2011). Environmental care in agriculture: A social perspective. Journal of Agricultural and Environmental Ethics 24: 243-258.

Sander, H. A. and Polasky, S. (2009). The value of views and open space: Estimates from a hedonic pricing model for Ramsey County, Minnesota, USA. Land Use Policy 26: 837-845.

Scarpa, R., Ferrini, S. and Willis, K. G. (2005). Performance of error component models for status-quo effects in choice experiments. In Scarpa, R. and Alberini, A. (eds), Applications of Simulation Methods in Environmental and Resource Economics. Dordrecht, The Netherlands: Springer, 247-273.

Schaafsma, M., Brouwer, R. and Rose, J. (2012). Directional heterogeneity in WTP models for environmental valuation. Ecological Economics 79: 21-31.

Schaafsma, M., Brouwer, R., Gilbert, A., van den Bergh, J. and Wagtendonk, A. (2013). Estimation of distancedecay functions to account for substitution and spatial heterogeneity in stated preference research. Land Economics 89: 514-537.

Schaafsma, M. (2015). Spatial and geographical aspects of benefit transfer. In Johnston, R. J., Rolfe, J., Rosenberger, R. S. and Brouwer, R. (eds), Benefit Transfer of Environmental and Resource Values. Dordrecht, The Netherlands: Springer, 421-439.

Street, D. J. and Burgess, L. (2007). The Construction of Optimal Stated Choice Experiments: Theory and Methods. Hoboken, USA: John Wiley \& Sons.

Swinton, S. M., Lupi, F., Robertson, G. P. and Hamilton, S. K. (2007). Ecosystem services and agriculture: Cultivating agricultural ecosystems for diverse benefits. Ecological Economics 64: 245-252.

Train, K. (2003). Discrete Choice Methods with Simulation. Cambridge, UK: Cambridge University Press.

Villanueva, A. J., Gómez-Limón, J. A., Arriaza, M. and Rodríguez-Entrena, M. (2015a). The design of agrienvironmental schemes: Farmers' preferences in southern Spain. Land Use Policy 46: 142-154. 
Villanueva, A. J., Gómez-Limón, J. A., Arriaza, M. and Rodríguez-Entrena, M. (2015b). Assessment of greening and collective participation in the context of agri-environmental schemes: The case of Andalusian irrigated olive groves. Spanish Journal of Agricultural Research 13: e0108.

Vuong, Q. H. (1989). Likelihood ratio tests for model selection and non-nested hypotheses. Econometrica 57: 307-333.

Yao, R. T., Scarpa, R., Turner, J. A., Barnard, T. D., Rose, J. M., Palma, J. H. N. and Harrison, D. R. (2014). Valuing biodiversity enhancement in New Zealand's planted forests: Socioeconomic and spatial determinants of willingness-to-pay. Ecological Economics 98: 90-101. 